$1989-12$

\title{
Healthy and Unhealthy Forms of Religiousness Manifested by Psychotherapy Clients: An Empirical Investigation
}

\author{
P. Scott Richards \\ Steven A. Smith \\ University of Minnesota - Twin Cities \\ Lanay F. Davis \\ University of Minnesota - Twin Cities
}

Brigham Young University - Provo, scott_richards@byu.edu

Follow this and additional works at: https://scholarsarchive.byu.edu/facpub

Part of the Student Counseling and Personnel Services Commons

\section{Original Publication Citation}

Richards, P.S., Smith, S.A., \& Davis, L.F. (1989). Healthy and unhealthy forms of religiousness manifested by psychotherapy clients: An empirical investigation. Journal of Research in Personality, 23, 506-524.

\section{BYU ScholarsArchive Citation}

Richards, P. Scott; Smith, Steven A.; and Davis, Lanay F., "Healthy and Unhealthy Forms of Religiousness Manifested by Psychotherapy Clients: An Empirical Investigation" (1989). Faculty Publications. 3869. https://scholarsarchive.byu.edu/facpub/3869 accepted for inclusion in Faculty Publications by an authorized administrator of BYU ScholarsArchive. For more information, please contact ellen_amatangelo@byu.edu. 


\title{
Healthy and Unhealthy Forms of Religiousness Manifested by Psychotherapy Clients: An Empirical Investigation
}

\author{
P. Scott Richards, Steven A. Smith, and Lanay F. Davis \\ University of Minnesota
}

\begin{abstract}
This study investigated whether 49 Mormon psychotherapy clients and 51 Mormon nonclients differed on a number of religious and psychological variables. The data were analyzed using analysis of covariance, controlling for social desirability, education level, and occupation status. Clients scored higher than nonclients on shame and lower on existential well-being. There were no significant differences between clients and nonclients on religious orientation, religious wellbeing, moral reasoning, and guilt. Females scored much higher on guilt, and female clients scored much higher on shame; there were no other gender differences. Subjects showed a preference for Stage 4 moral reasoning, and $92 \%$ were intrinsically motivated in their religious worship. The psychotherapy clients' religious beliefs and motivations appeared healthy and functional and could be an asset during therapy. The clients manifested some psychological issues which could predispose them to unhealthy reactions to some of the doctrines and influences of their religion. The gender differences observed were also discussed. (C) 1989 Academic Press, Inc.
\end{abstract}

The effects of religion on mental health and personality development and functioning have been a topic of considerable controversy in recent years (Bergin, Masters, \& Richards, 1987). Some psychologists have

This study was conducted while the authors were Ph.D. students in Counseling and Student Personnel Psychology in the Department of Educational Psychology at the University of Minnesota. The authors thank Alan R. Anderson, Michael J. Donahue, Lane Fischer, and Thomas J. Hummel for valuable comments they made on earlier drafts of this paper. Thanks are also due to our colleagues at the Mormon Counseling Clinic: Linda Cohen, Shirley Rutherford, Linda Solie, Mischel Walgren, and Linda Zimney for their assistance in collecting the data. Earlier versions of this paper, entitled "Healthy and Unhealthy Forms of Religiousness: A Comparison of Mormon Psychotherapy Clients and Mormon Nonclients," were presented at the Big Ten Counseling Center Conference at Michigan State University, East Lansing, MI, on February 20, 1986; at the annual convention of the American Psychological Association in Washington, DC, on August 26, 1986; and at the annual convention of the Association of Mormon Counselors and Psychotherapists in Salt Lake City, on October 2 and 3, 1986. Correspondence and requests for reprints should be addressed to Dr. P. Scott Richards, Department of Psychology, Central Washington University, Ellensburg, WA 98926. 
argued that religious beliefs, attitudes, or motivations can cause emotional disturbance (e.g., Ellis, 1980). Others have suggested that religiousness can interact with, and exacerbate, existing emotional problems (e.g., Moench, 1985). Other psychologists have contended, however, that religiousness can act as a therapeutic influence, or as a psychological resource, which facilitates personality development and helps to prevent or alleviate emotional disturbance (e.g., Bergin, 1980a, 1980b; Bergin et al., 1987; Duncan, Eddy, \& Haney, 1981; Maloney, 1985; Meadow \& Kahoe, 1984). While there are many unresolved issues at this stage of the research, it is clear that religiousness is a complex, multidimensional phenomenon (Bergin, 1983). Much research is still needed to clarify these complex relations.

Because of the deficiencies in the psychological literature concerning the relations between religiousness, personality, and mental health, and because of conceptual and attitudinal biases in counselor training programs, there is currently a rather widespread tendency for counselors and psychotherapists to view all kinds of religiousness manifested by their clients as either pathological or irrelevant (Bergin, 1983; Strommen, 1984). Beneficial or potentially therapeutic aspects of clients' religiousness tend to be overlooked. While some theoretical and research work has been done to identify and describe healthy and unhealthy forms and expressions of religiousness (e.g., Allen \& Spilka, 1967; Allport \& Ross, 1967; Ellison, 1983; James, 1902; Moench, 1985; Salzman et al., 1965), little is empirically known about what types of healthy or unhealthy religious beliefs, attitudes, or motivations individuals with psychological or emotional disorders actually manifest. More research about psychotherapy clients' religiousness, in particular, could help therapists better understand the various forms and expressions of religiousness their clients manifest during therapy, and thereby help therapists work more effectively with religiously committed clients.

The general purpose of the present study was to further investigate the relations between religiousness, personality, and mental health. The research questions we addressed were:

1. Do religious psychotherapy clients have religious beliefs or motivations which appear unhealthy or dysfunctional, or do their religious beliefs and motivations appear healthy and functional?

2. Do religious psychotherapy clients have personality characteristics or psychological issues which appear likely to interact in dysfunctional ways with their religious beliefs or motivations?

To investigate the first question, we administered to a group of psychotherapy clients, and for the sake of comparison, to a group of emotionally healthy, religious nonclients, the Religious Orientation Scale 
(ROS) (Allport \& Ross, 1967) and Spiritual Well-Being Scale (SWBS) (Ellison, 1983; Ellison \& Paloutzian, 1978). The ROS measures intrinsic and extrinsic religious orientation. Briefly, intrinsic people have internalized their religion and attempt to live it regardless of the external consequences. They are religious because they truly believe and because their beliefs endow their lives with meaning and unity. Extrinsic people, on the other hand, use their religion for their own ends. Their motivations for being religious are to obtain social status, security, and comfort. Research to date suggests that intrinsic religiousness tends to correlate positively with indices of healthy personality and emotional adjustment, while extrinsic religiousness tends to be negatively correlated, or uncorrelated, with such measures (Bergin et al., 1987; Donahue, 1985a). The SWBS provides a measure of religious well-being. Individuals who have religious well-being believe that God loves them and feel that their relationship with God is fulfilling and meaningful. Religious well-being, therefore, is a healthy religious belief or attitude (Ellison, 1983).

As mentioned earlier, many counselors and psychotherapists tend to perceive their clients' religious beliefs, attitudes, and motivations as unhealthy or pathological. We were interested in this study, therefore, to see if the psychotherapy clients would be more extrinsically religious, and have less favorable perceptions of their relationship with God, than would the nonclients.

To address the second research question above, we administered to the same subjects the Shame-Guilt Test A (SGTA) (Bupp, 1983; Korpi, 1977; Smith, 1972) and the Defining Issues Test (DIT) (Rest, 1979a). The SGTA measures shame and guilt. Shame has been defined as "an unpleasant emotional reaction by an individual to an actual or presumed negative judgment of himself by others" (Ausubel, 1955, p. 382). When individuals high on shame perceive that they have made a mistake or transgressed, they are likely to conclude that they are deficient and flawed (Anderson, 1974). Guilt "is a special kind of negative self-evaluation when an individual acknowledges that his behavior is at variance with a given moral value to which he feels obligated to conform" (Ausubel, 1955 , p. 379). The individual feeling guilt recognizes the act as bad, not the self as deficient or flawed (Anderson, 1974; Bupp, 1983). Thus, shame is viewed as an unhealthy response, and guilt as a healthy response, to a mistake or transgression. The DIT is based on Kohlberg's (1971) developmental theory and measures an individual's moral reasoning development. It is believed that those who score higher on the DIT reason about moral dilemmas or conflicts in a more conceptually adequate and comprehensive way (Rest, 1979a).

Shame, guilt, and moral reasoning development were psychological and personality variables which we believed might interact with reli- 
giousness in healthy or unhealthy ways. In this study, we were interested to see if psychotherapy clients were higher on shame and lower on moral reasoning development than were the nonclients. Such findings would suggest that the clients may be more predisposed to having unhealthy reactions to certain religious doctrines or influences. For example, theoretically, we would expect that individuals high on shame would tend to feel worse about themselves (conclude that they are inherently worthless and flawed) if they failed to live up to their religious values and beliefs. We would expect individuals who are low in moral reasoning development to find it more difficult to resolve complex religious and moral conflicts which they face, and thus, to experience more emotional distress from such conflicts.

Two other measures, the existential well-being subscale (EWB) of the SWBS and the Marlowe-Crowne Social Desirability Scale (MCS), were administered in this study. The EWB measures individuals' sense of life direction and satisfaction. The EWB scale has been found to be positively related to indices of emotional adjustment and mental health (e.g., selfesteem, perceived quality of parent-child relationships, childhood peer relationships, and social skills) and negatively related to indices of emotional disturbance (e.g., loneliness) (Ellison, 1983). The EWB scale, therefore, can be viewed as one indicator of emotional well-being (or disturbance) and served in this study as a condition check on whether the clients were more emotionally disturbed than were the nonclients. The MCS measures individuals' tendency to respond to test questions in a socially desirable fashion. It was administered in this study so that if clients and nonclients differed in their tendency to respond to the dependent measures in a socially desirable fashion, we could statistically control for this difference by using the MCS as a covariate in our analyses.

We also investigated whether men and women differed on the measures described above. According to some writers, the ideologies and socialization practices of many religious cultures have contributed to the victimization of women by men (Meadow \& Kahoe, 1984; Meadow, 1982; Shrock, 1984). If this is true, it raises the possibility that religion may operate differently in the lives of women and have different personality and mental health consequences for them. We felt, therefore, that it was important to look for possible differences between the Mormon men and women in this sludy.

\section{METHOD}

\section{Subjects}

Subjects were members of The Church of Jesus Christ of Latter-day Saints (Mormons) in the Minneapolis/St. Paul, Minnesota area. The client sample was composed of 49 people 
who were receiving psychotherapy at a Mormon counseling clinic in Minneapolis. According to MMPI diagnostic information and counselor diagnosis, the clients had sought therapy for a variety of problems and issues; 17 clients had serious marital problems, 14 had personality disorders, 10 had severe depression, 6 were sexual abuse victims, 3 were chemically dependent, 3 were emotional abuse victims, 1 had bipolar disorder, 1 had dysthymic disorder, 2 had anxiety disorders, and 1 manifested multiple phobias (totals do not add up to 49 because multiple problems were reported for some clients). The clients had been in therapy for varying lengths of time (anywhere from about 2 to 3 weeks up to approximately 18 months).

Clients attended church once a week, on the average. The majority of the clients were serving in nonpaid, nonleadership positions in their congregations. Thirty-six of the clients were females and 13 were males. The clients ranged in age from 19 to 57 years and had a mean age of 32.9 years. Ten of the clients were lifetime members of the Mormon church and 39 were converts. The modal yearly income level of the clients was $\$ 20-30,000$ and their modal education level was 1 to 2 years of college or technical training. Thirteen of the clients were employed in professional, technical, or managerial positions, 8 in "bluecollar" positions (skilled workers, operators, service, maintenance, craftsman), 8 in clerical or sales positions, and 20 were homemakers.

The nonclient sample was composed of 51 people who were not receiving therapy at the Mormon counseling clinic ${ }^{1}$ and who were serving in nonpaid leadership positions in local congregations of the Mormon church. ${ }^{2}$ On the average, leaders attended church once a week. Thirty of the nonclients were females and 21 were males. The nonclients ranged in age from 21 to 64 years and had a mean age of 37.6 years. Twenty-six of the nonclients were lifetime members of the Mormon church and 25 were converts. The modal income level of the nonclients was $\$ 30-40,000$, and the modal education level was 4 years of college (with degree). Twenty-four of the nonclients were employed in professional, technical, or managerial positions, 5 in "blue-collar" positions, 5 were in clerical or sales, and 17 were homemakers.

\section{Research Design}

A causal-comparative design (Borg \& Gall, 1979) was used in this study. The independent variables of interest were degree of emotional disturbance and sex, and the dependent variables of interest were the religious and personality measures mentioned earlier (see Measures section for detailed descriptions). Individuals in lay leadership positions were selected to compare with the clients because there is considerable research evidence supporting the notion that personal adjustment tends to be positively associated with leadership (Gibb, 1969; Mann, 1959; Stogdill, 1948). We believed, therefore, that it was likely that individuals serving in leadership positions, on the average, would be better adjusted emotionally, or in less emotional pain, than individuals in the client group. We felt less confident that this would be true of "nonleaders" randomly selected from the

\footnotetext{
1 The Mormon counseling clinic was set up solely for the purpose of providing therapy services to Mormons in the Minneapolis/St. Paul area. Mormons in this geographic region show a strong preference for working with therapists who have religious values and beliefs similar to their own (Richards \& Davison, 1989). Thus, there is a strong tendency for Mormons to seek counseling through the clinic and for church leaders to refer members of their congregations to the clinic. We felt confident, therefore, that few, if any, nonclients were actually psychotherapy clients receiving services elsewhere.

${ }^{2}$ Descriptions of the leadership positions and responsibilities associated with them are available at request from the senior author.
} 
general church membership. By selecting leaders, we increased the likelihood that the client group differed from the comparison group on the first independent variable. We also avoided the problem of religious inactivity in our comparison group. Weekly attendance rates in the Mormon church in the Minnesota area range between 50 to $60 \%$, so a random selection of individuals from the general church membership would have given us a large percentage of individuals who were not regular, or even occasional, church attenders.

\section{Procedure}

The study was conducted during fall, 1984. Permission to conduct the study was obtained from church leaders (the Stake Presidents) in the Minneapolis/St. Paul area. Sixty clients (the entire clientele) at the Mormon counseling clinic were given, by their therapist, a packet containing the dependent measures and explanatory cover letters which asked them to participate in the study. Forty-nine (82\%) of the clients actually completed and returned the measures.

Using a church directory which contained the names of all members of the Mormon church in the Minneapolis/St. Paul area, 61 individuals serving in leadership positions were randomly selected. These individuals were mailed packets of dependent measures and cover letters and were asked to participate in the study. Fifty-one (84\%) of the nonclients actually completed and returned the measures.

The packet of measures included (a) a cover letter endorsing the study from the subject's stake president; (b) a letter from the researchers which briefly explained the purpose of the study, solicited the subjects' participation, instructed the subjects to take the dependent measures in the order that they appeared in the packet, and told the subjects what to do with the measures after they completed them; (c) a consent form, which stressed that participation was voluntary, assured subjects that their responses would be kept confidential, and asked the subjects to sign a release indicating that they were voluntarily participating in the study; (d) a demographic questionnaire which asked subjects to provide information such as sex, age, income level, education level, and convert/nonconvert status; and (e) the dependent measures mentioned earlier. The order in which the dependent measures were placed in the packet was randomized to minimize order effects. Clients were instructed to seal the measures in an envelope after they completed them and give them to their therapist. Clients were informed in the letter from the researchers that the therapist would give the sealed envelope to the researchers without opening it. The nonclients were instructed to seal the measures in an envelope when they completed them and mail them directly to the researchers.

\section{Measures}

The Religious Orientation Scale (ROS) measures intrinsic and extrinsic religious orientation (Allport \& Ross, 1967). The ROS can be scored and analyzed in two ways. The first method involves calculating an intrinsic score (I) and an extrinsic score (E) and analyzing these two dimensions separately. The second method involves considering the two dimensions simultaneously in a fourfold classification system of "intrinsics" (high I, low E), "extrinsics" (low I, high E), "indiscriminants" (high I, high E), and "nonreligious" (low I, low E). Both of these scoring methods were used in this study. Reliabilities ranging from .69 to .93 have been reported for the ROS (Donahue, 1985b), and as one of the most frequently used measures of religiousness, a substantial amount of research exists which supports the construct validity of the instrument (e.g., Donahue, 1985a).

The Shame Guilt Test A (SGTA) was developed to provide researchers with an objective, self-report measure of shame and guilt. Bupp (1983) constructed the SGTA by refining and combining earlier shame/guilt measures developed by Smith (1972) and Korpi (1977). Bupp (1983) reported an internal consistency reliability of .91 for the shame scale and .92 for 
the guilt scale of the SGTA. For the sample used in this study, the internal consistency reliability of the shame scale was .87 and the guilt scale was .88 . Evidence supporting the validity of the SGTA has been reported by Bupp (1983), and research is currently in progress to further validate and expand the nomological network of the measure (Richards \& Williams, 1989b). The SGTA was used in this study because it was the only objective. self-report measure we were aware of which distinguishes between shame and guilt and provides a measure of both constructs.

The Defining Issues Test (DIT) was developed by Rest (1979a) to provide researchers with an objective test of moral reasoning ability. Internal consistency reliabilities in the high 70s and 80s have been reported for the DIT (Davison \& Robbins, 1978). In addition, extensive research has been done which supports the construct validity of the DIT (e.g., Rest, 1979a).

The Spiritual Well-Being Scale (SWBS) was developed by Ellison and Paloutzian (1978) and measures religious and existential well-being. Test-retest reliabilities for the religious and existential well-being subscales of .96 and .86 , respectively, have been reported, and internal consistency reliabilities of .87 and .75 , respectively have been reported for these subscales (Paloutzian \& Ellison, 1979). Evidence suporting the construct validity of the SWBS has also been reported (e.g., Ellison, 1983).

The Marlowe-Crowne Social Desirability Scale (Crowne \& Marlowe, 1960) is a well known measure which was developed to estimate individuals' tendency to respond to questions in a socially desirable fashion.

\section{Preliminary Analyses}

Preliminary analyses were done to determine which, if any, extraneous variables should be controlled for (used as covariates) in the main analyses. The criteria used to decide if a variable should be used as a covariate were (1) clients and nonclients and/or males and females significantly differed on the variable, and (2) the variable was significantly related to one or more of the dependent variables. The preliminary analyses revealed that the only three variables on which clients and nonclients and males and females differed, which were significantly related to one or more of the dependent variables, were social desirability, education level, and occupation status. Thus, these three variables were used as covariates in the main analyses.

\section{Main Analyses}

A multivariate analysis of covariance (ANACOVA) controlling for social desirability was conducted first to determine if clients and nonclients and males and females differed significantly on any of the dependent variables. Based on significant results on the multivariate test, univariate ANACOVAs controlling for social desirability were conducted.

Because clients and nonclients also differed on education level and occupation status, and these variables were significantly related to several of the dependent variables, it was difficult to attribute differences on the dependent variables solely to emotional status or sex when social desirability was the only covariate. In an attempt to overcome this problem, ANACOVAs controlling for social desirability, education level, and occupation status were also conducted. Finally, univariate analyses of variance (ANOVAs) were conducted so that unadjusted means, standard deviations, and $F$ tests could be compared with the adjusted means and $F$ tests from the ANACOVAs.

Using the theoretical medians of the intrinsic and extrinsic scales of the ROS as the cutpoints, as Donahue (1985a) has rccommended, subjects were classified as intrinsics, extrinsics, indiscriminants, and nonreligious based on their scores on the ROS. A chisquare analysis was done to determine if there was a significant relationship between the independent variables and religious orientation. Finally, mean DIT stage scores were 
computed for clients and nonclients and males and females so that we could see what type of moral reasoning the subjects preferred.

\section{RESULTS}

The Wilk's Lambda multivariate ANACOVA revealed that on the group of dependent religiousness and personality variables there was a significant difference between clients and nonclients, $F(7,87)=3.94$, $p=.0009$, and between males and females, $F(7,87)=4.29, p=.0004$, but there was not a significant interaction effect, $F(7,87)=0.15, p=$ 990. Based on these results, univariate ANOVAs and ANACOVAs ${ }^{3}$ were conducted comparing clients and nonclients and males and females on each of the religiousness and personality variables.

Because there were no significant interactions between therapy status and sex on either the multivariate or univariate analyses, separate tables are presented for client/nonclient and male/female comparisons. In Table 1 , the client/nonclient data are presented. When social desirability, education level, and occupation status were all controlled for (a) clients scored higher than nonclients on shame and (b) clients and nonclients did not significantly differ on guilt, intrinsic and extrinsic religiousness. religious well-being, and principled moral reasoning. Although clients scored higher than nonclients on shame, an inspection of the adjusted means revealed that the difference on shame between male clients $(M$ $=74.9)$ and both male $(M=69.1)$ and female nonclients $(M=71.3)$ was not particularly large. However, female clients $(M=95.1)$ scored considerably higher than male clients on shame and much higher than both male and female nonclients on shame.

When only social desirability was controlled for, clients also scored significantly lower than nonclients on religious well-being. When no covariates were used (ANOVA results), clients also scored significantly lower than nonclients on intrinsic religiousness.

In Table 2, the male/female data are presented. On all analyses, women scored much higher than men on guilt. On the rest of the variables, males and females did not significantly differ.

The fourfold classification of the subjects based on their ROS scores revealed that $42(86 \%)$ of the clients were intrinsics, $1(2 \%)$ was an extrinsic, $4(8 \%)$ were indiscriminants, and $2(4 \%)$ were nonreligious. Forty-nine (98\%) of the nonclients were intrinsics, $1(2 \%)$ was an indiscriminant, 0 were extrinsics, and 0 were nonreligious. Thirty-one of the

\footnotetext{
${ }^{3}$ The statistical assumptions required for analysis of covariance of homogeneity of regression slopes and whether there is a significant relationship between the covariate and dependent variables (Edwards, 1979) were tested for each of the dependent variables. On only one dependent variable were unequal regression slopes found. In this case, adjustments were made in the ANACOVA model to correct for the unequal slopes.
} 
TABLE 1

Client and Nonclient Unadjusted and Adjusted Means and $F$ Values on the Religious Orientation Scale (ROS), Spiritual Well-Being Scale (SWBS), Defining Issues Test (DIT), and Shame/Gullt Test A (SGTA)

\begin{tabular}{|c|c|c|c|c|c|}
\hline \multirow[b]{2}{*}{ Measure } & \multicolumn{2}{|c|}{ Clients $^{a}$} & \multicolumn{3}{|c|}{ Nonclients ${ }^{b}$} \\
\hline & $M$ & $S D$ & $M$ & $S D$ & $F$ \\
\hline \multicolumn{6}{|l|}{ Intrinsic (ROS) } \\
\hline Unadjusted & 37.6 & 5.4 & 39.8 & 3.2 & $5.37^{*}$ \\
\hline Adjusted $1^{c}$ & 37.6 & - & 39.5 & - & 3.44 \\
\hline Adjusted $2^{d}$ & 37.8 & - & 39,4 & - & 2.30 \\
\hline \multicolumn{6}{|c|}{ Extrinsic (ROS) } \\
\hline Unadjusted & 24.7 & 5.4 & 24.3 & 5.3 & 0.12 \\
\hline Adjusted 1 & 24.9 & - & 24.3 & - & 0.11 \\
\hline Adjusted 2 & 24.5 & - & 24.6 & - & 0.03 \\
\hline \multicolumn{6}{|c|}{ Religious well-being (SWBS) } \\
\hline Unadjusted & 48.5 & 9.2 & 53.0 & 6.3 & $5.31^{*}$ \\
\hline Adjusted 1 & 46.0 & - & 49.1 & - & $4.24^{*}$ \\
\hline Adjusted 2 & 46.2 & - & 49.1 & - & 3.70 \\
\hline \multicolumn{6}{|c|}{ Existential well-being (SWBS) } \\
\hline Unadjusted & 39.2 & 6.8 & 45.7 & 5.2 & $22.53^{* * *}$ \\
\hline Adjusted 1 & 39.6 & - & 45.4 & - & $17.30^{* * *}$ \\
\hline Adjusted 2 & 39.9 & - & 45.4 & - & $15.64^{* * *}$ \\
\hline \multicolumn{6}{|c|}{ Principled moral reasoning (DIT) } \\
\hline Unadjusted & 34.8 & 12.1 & 37.5 & 11.4 & 1.58 \\
\hline Adjusted 1 & 33.9 & - & 38.2 & - & 2.89 \\
\hline Adjusted 2 & 33.7 & - & 38.0 & - & 2.79 \\
\hline \multicolumn{6}{|c|}{ Shame (SGTA) } \\
\hline Unadjusted & 84.9 & 14.6 & 75.1 & 11.5 & $9.44^{* *}$ \\
\hline Adjusted 1 & 92.0 & - & 68.4 & - & $7.78^{* * *}$ \\
\hline Adjusted 2 & 89.5 & - & 70.4 & - & $3.92^{*}$ \\
\hline \multicolumn{6}{|l|}{ Guilt (SGTA) } \\
\hline Unadjusted & 124.6 & 14.8 & 122.1 & 15.8 & 0.01 \\
\hline Adjusted 1 & 125.0 & - & 121.5 & - & 0.15 \\
\hline Adjusted 2 & 124.6 & - & 122.3 & - & 0.01 \\
\hline
\end{tabular}

${ }^{a} n=49$.

${ }^{b} n=51$.

'Social desirability only covariate.

${ }^{d}$ Social desirability, education, occupation status all covariates.

$* p<.05$.

** $p<.01$.

$* * * p<.001$.

males were intrinsics, 1 was an indiscriminant, 1 was an extrinsic, and 0 were nonreligious. Sixty of the females were intrinsics, 4 were indiscriminants, 1 was an extrinsic, and 1 was nonreligious. A chi-square analysis revealed that there was not a significant relation between emotional status and religious orientation $(p=.149)$ or between sex and 
TABLE 2

Male and Female Unadjusted and adjusted Means and $F$ Values on the Religious Orientation Scale (ROS), Spiritual Well-Being Scale (SWBS), Defining Issues Test (DIT), and Shame/Gullt Test A (SGTA)

\begin{tabular}{|c|c|c|c|c|c|}
\hline \multirow[b]{2}{*}{ Measure } & \multicolumn{2}{|c|}{ Males" } & \multicolumn{3}{|c|}{ Females $^{b}$} \\
\hline & $M$ & $S D$ & $M$ & $S D$ & $F$ \\
\hline \multicolumn{6}{|l|}{ Intrinsic (ROS) } \\
\hline Unadjusted & 37.9 & 4.7 & 39.1 & 4.5 & 2.37 \\
\hline Adjusted $1^{r}$ & 37.8 & - & 39.1 & $一$ & 2.36 \\
\hline Adjusted $2^{d}$ & 37.9 & - & 39.0 & - & 1.07 \\
\hline \multicolumn{6}{|l|}{ Extrinsic (ROS) } \\
\hline Unadjusted & 24.6 & 4.8 & 24.5 & 5.6 & 0.04 \\
\hline Adjusted 1 & 24.6 & - & 24.6 & - & 0.01 \\
\hline Adjusted 2 & 25.2 & - & 24.2 & - & 0.40 \\
\hline \multicolumn{6}{|c|}{ Religious well-being (SWBS) } \\
\hline Unadjusted & 51.7 & 5.5 & 50.3 & 9.2 & 0.25 \\
\hline Adjusted 1 & 48.2 & - & 47.3 & - & 0.19 \\
\hline Adjusted 2 & 43.6 & - & 42.4 & - & 0.09 \\
\hline \multicolumn{6}{|c|}{ Existential well-being (SWBS) } \\
\hline Unadjusted & 43.5 & 5.6 & 42.0 & 7.4 & 0.15 \\
\hline Adjusted 1 & 43.5 & - & 42.1 & - & 0.18 \\
\hline Adjusted 2 & 43.6 & - & 42.4 & - & 0.09 \\
\hline \multicolumn{6}{|c|}{ Principled moral reasoning (DIT) } \\
\hline Unadjusted & 36.9 & 10.9 & 35.7 & 12.2 & 0.05 \\
\hline Adjusted 1 & 36.9 & - & 35.7 & - & 0.04 \\
\hline Adjusted 2 & 37.3 & - & 35.2 & - & 0.19 \\
\hline \multicolumn{6}{|l|}{ Shame (SGTA) } \\
\hline Unadjusted & 75.5 & 10.1 & 82.2 & 15.1 & 3.44 \\
\hline Adjusted 1 & 70.2 & - & 84.9 & -- & 3.11 \\
\hline Adjusted 2 & 71.4 & - & 84.0 & - & 2.55 \\
\hline \multicolumn{6}{|l|}{ Guilt (SGTA) } \\
\hline Unadjusted & 113.4 & 15.8 & 128.5 & 12.3 & $24.86^{* * *}$ \\
\hline Adjusted 1 & 113.3 & - & 128.4 & - & $25.35^{* * *}$ \\
\hline Adjusted 2 & 113.3 & - & 128.6 & - & $16.76^{* * *}$ \\
\hline \multicolumn{6}{|c|}{$\begin{array}{l}n=34 . \\
{ }^{a} n=66 . \\
\text { Social desirability only covariate. } \\
{ }^{d} \text { Social desirability, education, occupation status all covariates. } \\
{ }^{*} p<.05 \\
{ }^{* *} p<.01 \\
{ }^{* * *} n<001\end{array}$} \\
\hline
\end{tabular}

religious orientation $(p=.759)$. In total, $91(92 \%)$ of the subjects were intrinsically oriented in their religiousness.

Clients and nonclients and males and females differed very little on their DIT stage scores. The subjects tended to show a preference for Stage 4 moral reasoning (law and order orientation) as evidenced by their 
high overall Stage 4 raw score (24.9) and average overall principled moral reasoning score $(\mathrm{P} \%=36.2)$ relative to other samples (e.g., Martin, Shafto, \& Vandeinse, 1977; Rest, 1979b).

Finally, the clients scored significantly lower than the nonclients on existential well-being. This indicates that the clients tended to feel more confused and uncertain about the purpose and meaning of their lives, and they felt less satisfied and happy about the direction their lives were headed. The existential well-being scale of the SWBS has been found to be significantly positively related to self-esteem, perceived quality of parent-child relationships, family togetherness, childhood peer relationships, social skills, and negatively related to loneliness (Ellison, 1983). The finding that the clients scored lower on this measure, therefore, provides some empirical confirmation that the clients were more emotionally disturbed than were the nonclients.

\section{DISCUSSION}

This study has a number of limitations which should be kept in mind. The causal-comparative design does not allow definite conclusions about causation. The findings involving the SGTA need to be viewed with some tentativeness as the SGTA is an experimental instrument in need of further validation. Generalizations about the findings can only be made with confidence to Mormons in the Minneapolis/St. Paul area. The study needs to be repeated with Mormons in other geographic areas and with religious individuals from other faiths. Nevertheless, despite these cautions, a number of interesting conclusions relevant to theory, research, and practice are possible based on the findings of this study.

The first purpose of this study was to investigate whether the religious beliefs and motivations of religious psychotherapy clients appear unhealthy and dysfunctional, or healthy and functional. The findings of this study produced no evidence that the psychotherapy clients had unhealthy religious motivations, nor did it produce any evidence that the clients' beliefs and perceptions about their relationship with God were a source of emotional distress for the clients.

The clients were as intrinsically oriented (high intrinsic scores and low extrinsic scores) in their religiousness as were the nonclients in this study, and as much, or even more, intrinsically oriented than some other nonclinical samples which have been reported in the literature (e.g., Bergin et al., 1987). This indicates that these psychotherapy clients have internalized their religion and are attempting to live it in their daily lives. Their motivations for being religious tend not to be instrumental and self-serving, but rather, selfless and meaning-endowing (Allport \& Ross, 1967; Donahue, 1985a). Intrinsic religiousness certainly does not prevent or completely cure psychological problems or the clients in this study 
would not have needed to obtain psychotherapy. However, clients' intrinsic religious participation appears to be a therapeutic influence, and if discerned by therapists, could be an asset during psychotherapy (Bergin et al., 1987).

When education level and occupation status differences were controlled, the clients did not differ from the nonclients in this study on religious well-being. The clients' religious well-being scores also did not differ much from the scores of predominantly Catholic and Lutheran undergraduate students at the University of Minnesota-Duluth (UMD) who were classified based on their ROS scores as intrinsically religious $(M=51.7)$ and indiscriminantly proreligious $(M=49.8)$ (Richards \& Williams, 1989a). The clients' religious well-being scores were also considerably higher than the scores of the nonreligious $(M=36.8)$ and extrinsically religious students ( $M=41.6)$ at UMD (Richards \& Williams, 1989a).

The clients' relatively high religious well-being scores indicate that despite their problems, the clients felt that their relationship with God gives them strength, helps them cope, and contributes to their well-being. The clients' favorable perceptions of their relationship with God, and the meaning, satisfaction, and fulfillment they feel from this relationship would appear, therefore, to be a beneficial influence in their lives. Therapists who are willing to enter into their client's religious world view to seek to understand the client's perceptions of God, could discover that the client's relationship with God can be used therapeutically, just as other meaningful relationships in clients' lives can often be used for therapeutic leverage.

While this study produccd no cvidence that psychotherapy clients have religious beliefs, attitudes, or motivations which cause or contribute to their emotional disturbance, it of course, does not rule out this possibility. As practicing clinicians ourselves, we would be very surprised if such evidence is not found.

The second purpose of this study was to investigate whether there was any evidence that religious psychotherapy clients have personality traits or psychological issues which appear likely to interact in dysfunctional ways with their religious beliefs or attitudes. The findings relevant to this second research question were rather mixed, and less straightforward to interpret than the findings relevant to the first research question posed in this study. Nevertheless, some useful conclusions and speculations were possible.

The finding that the psychotherapy clients did not differ on their moral reasoning scores from the nonclients suggests that the clients were no more likely to experience emotional conflict or distress due to inabilities to resolve complex moral dilemmas than were the nonclients. A deficit 
in moral reasoning development was apparently not a cause of the clients' emotional disturbance.

The finding that the Mormon subjects showed a clear preference for Stage 4 moral reasoning was not surprising, considering the fact that in Mormon theology, obedience to law, both moral and civil, is a fundamental tenet (Talmage, 1890/1977). Other researchers have also found that individuals who are active in conservative religious groups tend to prefer Stage 4 moral reasoning (Getz, 1984; Richards, 1988).

Research by Hogan (1973) suggests that individuals who prefer "the ethics of responsibility" (Stage 4) tend to be "reasonable, helpful, and dependable; on the other hand, they often seem conventional and resistant to change" (p. 225). Religious individuals who are conventional, resistant to change, and who believe strongly in respecting authorities, a characteristic of Stage 4 thinkers (Rest, 1979a, p. 31), may be hesitant to question or challenge these authorities (parents, church leaders, and church regulations and doctrines) even when obedience to the authorities may be maintaining or contributing to their problems. In this respect, therefore, the psychotherapy clients' strong preference for Stage 4 moral reasoning could have been a liability for them during the psychotherapy process.

In working with Mormon clients the past few years, it has been our clinical observation that some clients have a tendency to misunderstand or oversimplify church leaders' statements and church doctrines. Some of the clients' misunderstandings seem to be due to a lack of knowledge of the church doctrine. It also appears that problems arise because simplistic religious concepts and beliefs which the clients acquired as children, or early in their church membership, have not been critically examined, challenged, and modified. Individuals who strongly believe in respecting authorities will probably not be very inclined to critically examine and challenge beliefs and concepts they acquired from the authority figures in their lives. Personality development and psychological health could be jeopardized by the unwillingness of such individuals to examine religious beliefs and concepts which are dysfunctional for them.

On the other hand, the strong belief some religious individuals have in respecting authorities could be functional and healthy for them in other ways. For example, this characteristic could keep such individuals from acting out in a destructive, antisocial, or illegal manner. In this light, it is interesting that religious involvement tends to be negatively related to social problems such as drug abuse, sexual permissiveness, alcohol abuse, and deviant or delinquent social acts (Batson \& Ventis, 1982; Bergin, 1983; Spilka, Hood, \& Gorsuch, 1985). This may be due, in part at least, to the emphasis most religions place on respecting law and authority. 
The finding that the shame scores of the psychotherapy clients were significantly higher than those of the nonclients in this study indicates that the clients reported the tendency to feel more exposed, bad, deficient, and humiliated when they make a mistake or transgress (Anderson, 1974; Bupp, 1983) than did the nonclients. The psychotherapy clients' shame scores were slightly higher (though not statistically different) than the shame scores reported by Bupp (1983) for Vietnam veterans $(M=$ 82.2), many of whom reported having psychological problems. The clients' shame scores were also slightly higher (though not statistically different) than those observed in a large group of predominantly Catholic and Lutheran undergraduate students at the UMD $(M=83.0)$ (Richards \& Williams, 1989b). The subjects at UMD were much younger (average age about 20 years) than the client $(M=32.9$ years) and veteran $(M=$ 34 years) samples which could explain their high shame scores; Bupp (1983) noted that adolescents and young adults tend to score higher on the shame scale than older adults.

One implication of the psychotherapy clients' relatively higher shame response, compared to the nonclients in this study at least, is that it could mean they are more prone to feeling discouraged and depressed when they perceive that they have failed to live up to the expectations of their religious leaders and doctrines. A number of theorists have suggested that shame is closely linked, perhaps causally, with depression (e.g., Barry, 1962, Lewis, 1971; Wallace, 1963). Some empirical support for the positive relation between shame and depression was provided by Richards \& Williams (1989b) when they found that the shame scale of the SGTA correlated positively $(r(262)=.34, p<.001)$ with the Center for Epidemiological Studies Depression Scale (Radloff, 1977).

The third purpose of this study was to investigate whether there were any gender differences on the measures to see if there was any evidence that religion was operating differently in the lives of the women, and having different mental health consequences for them. As noted above, females, as much so as males, were intrinsically motivated in their religious worship and reported that their relationship with God was meaningful and fulfilling. Females also did not differ from males on the moral reasoning measure.

However, while the females collectively did not differ from the males on the shame scale of the SGTA, as noted above, a subgroup of female clients scored much higher on shame than anyone else. The only other noteworthy difference between males and females in this study was that females scored much higher than males on guilt. Both the Mormon female and male guilt scores in this study were higher than the Vietnam veteran guilt scores $(M=104.1)$ reported by Bupp (1983), and they were higher than the male $(M=102.8)$ and female $(M=112.1)$ guilt scores for UMD 
undergraduates observed by Richards \& Williams, (1989b). Interestingly, the large gender difference found on guilt in this study was also observed by Richards \& Williams, (1989b) on their UMD sample, $F(1,222)=$ $16.98, p<.001$.

The finding that the female clients were so high on shame, as well as guilt, indicates that these women reported a much stronger tendency than the nonclients, and even the male clients, to feel bad, exposed, guilty, and deficient when they make a mistake or transgress. As discussed above, a strong shame response may make individuals more prone to feeling discouraged and depressed when they perceive they have failed to live up to their religious beliefs and values. Guilt and shame are closely related phenomena; one response is often accompanied by the other (Ausubel, 1955; Bupp, 1983; Levin, 1967). Those who are high on both shame and guilt are probably unlikely to experience guilt without having maladaptive feelings of shame and worthlessness triggered by the guilt. These female clients would appear particularly likely, therefore, to feel discouraged and depressed by real or imagined failures to live up to their religious values.

In light of this finding, it is interesting to note that within the Mormon culture, it has been observed by some that the Mormon doctrine of "striving for perfection," and the tendency in the Mormon culture to frequently preach about "duties" and "responsibilities," appear to cause some Mormon women to feel inadequate and unworthy, and that these feelings then contribute to the onset of discouragement and depression (Degn, Yeates, Greenwell, \& Fiddler, 1985). Many other Mormon women, however, do not appear to be adversely affected by these cultural influences (Rasmussen, 1985). It may be that the doctrinal and cultural influences which motivate some women, contribute to the discouragement and depression of women who are high on shame. Research is needed to investigate this possibility directly by comparing women who are high on shame with women who are low in shame to see if they differ in their reactions to various religious doctrines or cultural influences.

The finding that the Mormon females, as well as UMD females, scored much higher on guilt than the males indicates that these women report feeling more sorrow and guilt when they violate their moral or ethical standards than do males. This is an interesting finding, which we feel raises two important questions. First why do females tend to score so much higher than males on guilt, and second, what are the mental health consequences of females having such a strong guilt response?

In trying to understand why women scored higher than men on guilt, Gilligan's (1982) theory that women reason differently about morality than men seemed meaningful. Gilligan (1982) described women's morality 
as an "ethics of care" which focuses on caring and responsibility in relationships and men's morality as an "ethics of justice" which focuses on abstract principles of equality and rights. According to Gilligan's theory, therefore, women might be expected to feel more guilt for violations of trust and care in relationships than would men. Interestingly, the guilt scale of the SGTA, to a large degree, seems to be measuring a "morality of relationships." About half of the items on the scale asked respondents to indicate how badly they would feel after having deceived or hurt a close friend or family member. Many of the other items also seem to be measuring an ethics of relationships.

In light of this, the finding that women scored higher than men on guilt in this study, and in the Richards \& Williams (1989b) study, seems understandable. The findings of other researchers (e.g., Brock \& Buss, 1964; Buss \& Brock, 1963; Frodi, Macaulay, \& Thome, 1977) that women tended to feel more guilt than did males for acts of aggression which they committed against others are consistent with our findings and also seem to support Gilligan's theory.

A number of theorists and researchers have pointed out that there are both functional and pathological forms of guilt (Bergin 1980a, 1980b; Mowrer, 1961; Sacks, 1985). The SGTA is thought to measure an appropriate guilt response for transgrcssions that one has committed (Bupp, 1983). An appropriate guilt response is functional because it leads to restitution and because the individual feeling the guilt recognizes the act as bad, not the self as bad (Anderson, 1974; Bupp, 1983). There is some empirical evidence to support the notion that the guilt scale of the SGTA does not correlate with psychopathology. The guilt scale of the SGTA was only weakly correlated with depression $(r(245)=.18, p<.01)$ and it was essentially uncorrelated (as opposed to negatively correlated) with existential well-being $(r(250)=.06, p=.186)$ (Richards \& Williams, 1989b). In additon, in the present study, the psychotherapy clients did not score higher on guilt than did the nonclients, which also suggests that a strong guilt response on the SGTA is not positively related to psychological disturbance. More research investigating the psychological correlates of the SGTA would be valuable in that it would contribute to our understanding of this interesting gender difference.

\section{REFERENCES}

Allen, R. O., \& Spilka, B. (1967). Committed and consensual religion: A specification of religion-prejudice relationships. Journal for the Scientific Study of Religion, 6, 191206.

Allport, G. W., \& Ross, J. M. (1967). Personal religious orientation and prejudice. Journal of Personality and Social Psychology, 5, 432-443.

Anderson, A. R. (1974). Guilt and shame. Unpublished manuscript, University of Minnesota, Department of Educational Psychology, Minneapolis. 
Ausubel, D. P. (1955). Relationships between shame and guilt in the socializing process. Psychological Review, 62, 378-390.

Barry, M. J. (1962). Depression, shame, loneliness and the psychiatrist's position. American Journal of Psychotherapy, 16, 580-590.

Batson, C. D.. \& Ventis. W. L. (1982). The religious experience: A social-psychological perspective. New York: Oxford.

Bergin, A. E. (1980a). Psychotherapy and religious values. Journal of Consulting and Clinical Psychology, 48, 95-105.

Bergin, A. E. (1980b). Religious and humanistic values: A reply to Ellis and Walls. Journal of Consulting and Clinical Psychology, 48, 642-645.

Bergin, A. E. (1983). Religiosity and mental health: A critical reevaluation and metaanalysis. Professional Psychology: Research and Practice, 14, 170- 184.

Bergin, A. E., Masters, K. S., \& Richards, P. S. (1987). Religiousness and mental health reconsidered: A study of an intrinsically religious sample. Journal of Counseling Psychology, 34, 197-204.

Borg, W. R., \& Gall, M. D. (1979). Educational research: An introduction. New York: Longmans.

Brock, T. C., \& Buss, A. H. (1964). Effects of justification for aggression and communication with the victim on post aggression dissonance. Journal of Abnormal and Social Psychology, 4, 403-412.

Bupp, C. S. (1983). An examination of shame and guilt among veterans of the Vietnam conflict. Unpublished doctoral dissertation, University of Minnesota, Minneapolis

Buss, A. H., \& Brock, T. C. (1963). Repression and guilt in relation to aggression. Journal of Abnormal and Social Psychology, 4, 345-350.

Crowne, D. P.. \& Marlowe, D. (1960). A new scale of social desirability independent of psychopathology. Journal of Consulting Psychology, 24, 349-354.

Davison, M. L., \& Robbins, S. (1978). The reliability and validity of objective indices of moral development. Applied Psychological Measurement, 2, 391-403.

Degn, L., Yeates, E. Greenwell, B., \& Fiddler, L. (1985). Mormon women and depression [Transcript of KSL-TV (Salt Lake City) documentary]. Sunstone, 10, 19-27.

Donahue. M. J. (1985a). Intrinsic and extrinsic religiousness: Review and meta-analysis. Journal of Personality and Social Psychology, 48, 400-419.

Donahue, M. J. (1985b). Intrinsic and extrinsic religiousness: The empirical research. Journal for the Scientific Study of Religion, 24, 418-432.

Duncan, H. D., Eddy, J. P., \& Haney, C. W. (1981). Using religious resources in crisis intervention. Counseling and Values, 25, 178-191.

Edwards, A. L. (1979). Multiple regression and the analysis of variance and covariance. San Francisco: Freeman.

Ellis, A. (1980). Psychotherapy and atheistic values: A response to A. E. Bergin's "Psychotherapy and Religious Values." Journal of Consulting and Clinical Psychology, 48, 635-639.

Ellison, C. W. (1983). Spiritual well-being: Conceptualization and measurement. Journal of Psychology and Theology, 11, 330-340.

Ellison, C. W., \& Paloutzian, R. F. (1978, August). Assessing quality of life: Spiritual well-being. Paper presented at the annual meeting of the American Psychological Association, Toronto.

Frodi, A., Macaulay, J., \& Thome, P. R. (1977). Are women always less aggressive than men? A review of the experimental literature. Psychological Bulletin, 84, 634-660.

Getz, I. R. (1984). Moral judgment and religion: A review of the literature. Counseling and Values, 28, 94-116.

Gibb, C. A. (1969). Leadership. In G. Lindzey \& E. Aronson (Eds.), Handbook of social psychology (2nd ed.). Reading, MA: Addison-Wesley. 
Gilligan, C. (1982). In a different voice: Psychological theory and women's development. Cambridge, MA: Harvard Univ. Press.

Hogan, R. (1973). Moral conduct and moral character. Psychological Bulletin, 79, 217 232.

James, W. (1902). The varieties of religious experience. New York: Longmans.

Kohlberg. L. (1971). From is to ought: How to commit the naturalistic fallacy and get away with it in the study of moral development. In T. Mischel (Ed.), Cognitive development and epistemology. New York: Academic Press.

Korpi, D. R. (1977). Psychohistorical aspects of shame and guilt as functions of political ideology (Doctoral dissertation, California School of Professional Psychology, 1977). Dissertation Abstracts International, 38, 2866B.

Levin, S. (1967). Some metapsychological considerations on the differentiation between shame and guilt. International Journal of Psychoanalysis, 48, 267-276.

Lewis, H. B. (1971). Shame and guilt in neurosis. New York: Intern. Univ. Press.

Maloney, H. N. (1985). Assessing religious maturity. In E. M. Stern (Ed.), Psychotherapy and the religiously committed patient. New York: Haworth.

Mann, R. D. (1959). A review of the relationships between personality and performance in small groups. Psychological Bulletin, 56, 241-270.

Martin, R. M., Shafto, M., \& Vandeinse, W. (1977). The reliability and validity and design of the Defining Issues Test. Developmental Psychology, 13, 460-468.

Meadow, M. J. (1982). True womanhood and women's victimization. Counseling and Values, 26, 93-101.

Meadow, M. J.. \& Kahoe, R. D. (1984). Psychology of religion: Religion in everyday lives. New York: Harper \& Row.

Moench, L. A. (1985). Mormon forms of psychopathology. AMCAP Journal, 11, 61-73.

Mowrer, O. H. (1961). The crisis in psychiatry and religion. New York: Van NostrandReinhold.

Paloutzian, R. F., \& Ellison, C. W. (1979). Developing a measure of spiritual well-being. In R. F. Paloutzian (Chair), Spiritual well-being, loneliness, and perceived quality of life. Symposium presented at the annual meeting of the American Psychological Association, Toronto.

Radloff, L. (1977). The CES-D scale: A new self-report depression scale for research in the general population. Applied Psychological Measurement, 1, 385-401.

Rasmussen, D. M. (1985). AMCAP men and women: Together in mutual respect and unity. AMCAP Journal, 11, 29-39.

Rest, J. R. (1979a), Development in judging moral issues. Minneapolis: Univ. of Minnesota Press.

Rest, J. R. (1979b). Revised manual for the Defining Issues Test: An objective test of moral development. Minneapolis: Minnesota Moral Research Projects.

Richards, P. S. (1988). The relation between principled moral reasoning and conservative religious ideology: $A$ critical reevaluation and investigation of test item bias in the Defining Issues Test. Unpublished doctoral dissertation, University of Minnesota, Minneapolis.

Richards, P. S., \& Davison, M. L. (1989). The effects of theistic and atheistic counselor values on client trust: A multidimensional scaling analysis. Counseling and Values, $33,109-120$.

Richards, P. S., \& Williams, R. C. (1989a). The relation of religious orientation with depression, shame, guilt, and spiritual well-being. Manuscript in preparation.

Richards, P. S., \& Williams, R. C. (1989b). Construct validation of the Shame-Guilt Test. Manuscript in preparation.

Sacks, J. M. (1985). Religious issues in psychotherapy. Journal of Religion and Health, 24, 26-29. 
Salzman, L., et al. (1965). Healthy and unhealthy patterns of religion. Journal of Religion and Health, 4, 322-344.

Shrock, D. A., (1984). Suppression of women by religion. Counseling and Values, 29, 4958.

Smith. R. L. (1972). The relative proneness to shame or guilt as an indicator of defensive style (Doctoral dissertation, Northwestern University, 1972). Dissertation Abstracts International, 33, 2823B-2824B.

Spilka, B., Hood, R. W., \& Gorsuch, R. L. (1985). The psychology of religion: An empirical approach. Englewood C'lifts, NJ: Prentice-Hall.

Stogdill, R. M. (1948). Personal factors associated with leadership: A survey of the literature. Journal of Psychology, 25, 35-71.

Strommen. M. P. (1984). Psychology's blind spot: A religious faith. Cotunseling and Values, 28, 150-161.

Talmage, J. E. (1890/1977). The Articles of Faith. Salt Lake City, UT: Deseret Press.

Wallace, L. (1963). The mechanism of shame. Archives of General Psychiatry, 8, 80-85. 